\title{
DE LA FIESTA DE INOCENTES A LA DIABLADA PILLAREÑA. LOS CAMBIOS EN UNA FIESTA PATRIMONIAL DEL ECUADOR, $1990-2020$
}

\author{
From La Fiesta de Inocentes to the Diablada Pillareña. Changes \\ in a Heritage Festival of Ecuador, 1990-2020
}

\section{FERNANDO ENDARA*}

Fecha de recepción: 27 de febrero de 2021 - Fecha de aprobación: 15 de junio de 2021

\section{Resumen:}

La Diablada Pillareña es una celebración popular y patrimonial de la ciudad de Pílaro, provincia de Tungurahua, en Ecuador, que se realiza los primeros seis días de cada año. Para estudiarla utilizo un método autoetnográfico que aprovecha mis memorias cognitivo-afectivas de la fiesta como participante bailador implicado, cuya historia de vida, después de 15 años de baile, está atravesada por la diablada. Sigo a Gisela Cánepa Koch en su idea de la cultura expresiva, un concepto y un método que no busca significados ancestrales, esenciales, míticos o preestablecidos en las celebraciones andinas, sino que se interesa por los significados prácticos que se ponen en juego y que se actualizan en cada diablada. Para buscar las alteraciones de la diablada en el período 1990-2020, sigo a Alejandro Diez Hurtado, que propone tres tipos de cambios en las festividades andinas: cambios periféricos, cambios complementarios y cambios desestructurantes. Encuentro así dos momentos desestructurantes: la eliminación de los enfrentamientos a inicios de la década de 1990 y la declaratoria patrimonial de la fiesta de 2008.

Palabras clave: patrimonio inmaterial; Diablada Pillareña; celebración andina; cultura expresiva; declaratoria patrimonial.

\section{Abstract:}

The Diablada Pillareña is a popular and patrimonial celebration of the city of Pillaro, province of Tungurahua in Ecuador, that takes place the first 6 days of every year. To interpret la Diablada Pillareña I use an autoethnographic method, which takes advantage of my cognitive-affective memories of the festival, as an involved participant dancer, whose life story, after 15 years of dancing, is crossed by the diablada. I follow Gisela Cánepa Koch, in her idea of expressive culture, a concept and a method that does not look for ancestral, essential, mythical or pre-established meanings in Andean celebrations, but is interested in the practical meanings that are put into play and that are actualized in each diablada. To look for changes in the diablada in the period 1990-2020, I follow Alejandro Diez Hurtado who proposes 3 types of changes in Andean festivities: peripheral changes, complementary changes and destructuring changes. I find two destabilizing moments: the elimination of the confrontations at the beginning of the 1990s, and the Patrimonial Declaration of the 2008 festival.

Keywords: intangible heritage; Diablada Pillareña; Andean celebration; expressive culture; heritage statement.

* Mg. de Investigación en Antropología. Facultad Latinoamericana de Ciencias Sociales, Ecuador. Correo-e: fernandodaveendara@gmail.com 


\section{Introducción}

La Diablada Pillareña es una celebración popular y patrimonial que se lleva a cabo en la ciudad de Píllaro, provincia de Tungurahua en Ecuador, los primeros seis días de cada año, es decir, del 1 al 6 de enero. Esta fiesta, de arraigada tradición en la costumbre pillareña, fue proclamada patrimonio cultural inmaterial (intangible) (PCl) del Ecuador el 29 de diciembre de 2008. Cientos de personas conforman grupos de baile o comparsas denominadas partidas, que representan a los barrios o caseríos rurales, campesinos o periféricos del cantón ${ }^{1}$. Cada partida tiene una banda de pueblo ${ }^{2}$ y varios disfrazados o personajes: diablos ${ }^{3}$, parejas de línea ${ }^{4}$, guarichas $^{5}$, capariches ${ }^{6}$ y chorizos ${ }^{7}$; cada disfrazado sigue un código específico y particular en la fiesta.

Las partidas se concentran en sus respectivos barrios o caseríos y "bajan" o se desplazan bailando desde estos lugares rurales, campesinos o periféricos hasta el centro de la ciudad, para tomarse, con bailes y símbolos (Espín, 2019), las calles principales del casco urbano, las calles de la administración política y religiosa, la vía pública por excelencia, el contorno del parque y la iglesia. Las partidas ${ }^{9}$ se toman de manera simbólica la ciudad para recordar el importante papel de los habitantes de los barrios rurales, caseríos o periféricos que, asociados a la agricultura y la ganadería, son el sustento alimenticio, económico y cultural del cantón (Espín, 2019; N. Bonilla, entrevista personal, 18 nov. 2019). Después de recorrer bailando estas calles, las partidas se dirigen a su "descanso" o "posada". Luego de un tiempo aproximado de dos horas, los disfrazados salen de nuevo, para hacer su recorrido característico y regresar a sus barrios o caseríos para el remate o compartir final.
El cantón Santiago de Píllaro se encuentra a $12 \mathrm{~km}$ de la ciudad de Ambato, capital de la provincia de Tungurahua y a $105 \mathrm{~km}$ de Quito, capital del Ecuador. Píllaro se encuentra a 2.800 msnm en la estribación occidental de la CordiIlera Central de los Andes, con una posición de 1 10' de latitud sur y 78 32' de longitud oeste, extensión en la que ocupa diversos pisos climáticos que van desde el clima subhúmedo de las estribaciones de la cordillera a 2.100 msnm, pasando por un clima templado, hasta el frío páramo andino a $4.000 \mathrm{msnm}$. Su promedio de precipitación anual es de $70 \mathrm{~mm}$. Píllaro limita al sur con los cantones de Patate y Pelileo, al norte con la provincia de Cotopaxi, al este con la provincia de Napo y al oeste con el cantón Ambato. Está conformado por dos parroquias urbanas: la Matriz y Ciudad Nueva, y siete parroquias rurales: Baquerizo Moreno, San José de Poaló, Emilio María Terán, San Miguelito, San Andrés, Marcos Espinel y Presidente Urbina. La extensión territorial de Píllaro es de $443,1 \mathrm{~km}^{2}$, establecida por el Instituto Geográfico Militar (Campaña, Rosa, Ron \& Robalino, 2010).

Según el último censo poblacional del Instituto Nacional de Estadística y Censos (INEC), Píllaro tiene una población de 38.357 habitantes: 18.091 hombres y 20.266 mujeres. La mayor parte se considera mestiza. El sector urbano reúne a $19,4 \%$ de la población y el rural, 80,6 \% (INEC, 2014). Entre las actividades económicas destacan las relacionadas con la agricultura, la ganadería, la silvicultura y la pesca, que implican $48,9 \%$ de las actividades económicas de los pillareños y pillareñas, seguidas por la construcción (10,9\%), el comercio al por mayor y menor $(9,6 \%)$, las industrias manufactureras $(9,0 \%)$ y el sector del transporte (4,7\%) (INEC, 2014). 
La Diablada Pillareña tiene su origen en sitios locales y rurales: el barrio Tunguipamba y la parroquia Marcos Espinel (Espín, 2019; Bonilla, entrevista personal, 18 nov. 2019; Landy, 2019). Los motivos del baile refieren a antiguas disputas amorosas entre Tungupamba y Marcos Espinel (T. Chasi, entrevista personal, 8 dic. 2019), a enfrentamientos rituales (Bonilla, 2019; Reino, 2006) y a una toma simbólica de las calles centrales por parte de los pobladores periféricos, rurales o campesinos (Bonilla, 2019; Espín, 2019).

\section{La Diablada Pillareña como cultura expresiva}

Los carnavales, diabladas, morenadas, fiestas de santos, santas, vírgenes, entre otros, pueden ser tratados como formas de cultura expresiva (Cánepa Koch, 2001). Este concepto hace referencia a la interacción entre performance, memoria y experiencia (Cánepa Koch, 2001). Una fiesta andina y/o popular puede ser entendida como una forma de cultura expresiva que requiere una puesta en escena o una puesta en práctica "que genera experiencias mientras crea significados y viceversa" (Cánepa Koch, 2001, p. 12). No se trata entonces de analizar los significados que se esconden debajo de una careta o de un tipo de danza, ni tampoco de buscar aspectos rituales y simbólicos ligados a una etnicidad ancestral que esencializa las prácticas culturales, sino de verificar un acto comunicativo, una experiencia y una expresión que interioriza significados ideales y materiales en los cuerpos de los y las participante. La cultura expresiva no tiene un texto o significado preestablecido, se realiza en los actos, en el baile, en la música, en el disfraz, en el ritual (Cánepa Koch, 2001).
Esta perspectiva intenta un abordaje teórico y metodológico distanciado de los trabajos clásicos sobre festividades andinas, que buscan la continuidad de formas prehispánicas en los cantos y los bailes, elementos y significados ocultos o "auténticos" en los disfraces o caretas, o una supuesta esencia andina contestataria al sistema económico y social. Este tratamiento no busca el significado arraigado, mítico o "real" de las danzas como objetos coleccionables, catalogables, como bienes de museo descontextualizados; al contrario, busca procesos y experiencias intersubjetivas que tienen la capacidad de generar significados e inscribirlos en el cuerpo (Cánepa Koch, 2001, p. 15). Esta visión permite el mismo abordaje teórico-metodológico para el tratamiento de danzas, fiestas populares, carnavales, morenadas, diabladas y rituales, porque descubre significados actuales y no míticos, posibles únicamente en el tiempo y el espacio de su realización; entonces, cada ejecución performativa es única, específica y contextualizada.

El énfasis de la cultura expresiva es su ejecución, que depende de un contexto. Los y las participantes de una danza, diablada o fiesta toman en cuenta el contexto de la representación, esto es, a los observadores y la coyuntura. "Existe una negociación entre el agente responsable de la performance y la audiencia que lo interpreta, acepta o rechaza [...] un carácter reflexivo en la puesta en escena y una dimensión política" (Cánepa Koch, 2001, p. 17). Se trata de una doble contextualización: la danza, al ser interpretada, crea el contexto de la ejecución, su primer nivel: el lugar y momento de la representación, la geopolítica local, nacional y mundial, la historia reciente, la conformación de identidades en la región, la audiencia a quien se dirige, entre otros; pero en su segundo nivel, la contextualización 
se refiere a la representación: lo que hacen los agentes con el contexto, la responsabilidad que asumen: "ponen a juicio de la audiencia la performance y a sí mismos, como agentes de la representación" (Cánepa Koch, 2001, p. 17). Son, así, autorreferenciales, sarcásticos, jocosos, creativos, críticos y/o reflexivos.

En ningún caso el primer o el segundo nivel de contextualización son realidades preexistentes o delimitadas. Se establecen de forma histórica, sí, pero responden a procesos complejos de relación entre los agentes, o entre los agentes y la audiencia, que se actualizan, cambian o continúan en cada performance. En la Diablada Pillareña, el primer nivel de contextualización sería Píllaro y su geopolítica local, regional, nacional y global. También, la historia particular y la conformación de identidades de la región y de la ciudad, la historia de vida de los y las participantes y de los y las observadoras, la coyuntura política, económica y social específica del año en curso y, por supuesto, las lógicas, las costumbres y las dinámicas propias de la diablada, con sus cambios periféricos, complementarios y/o desestructurantes (Diez Hurtado, 2001), entre otros.

El segundo nivel de contextualización sería lo que los participantes hacen con sus cuerpos dentro de ese primer contexto: ¿Cómo elaboran las caretas? ¿Por qué se crean, modifican o actualizan las caretas y los disfraces cada año? ¿Qué gritos y vivas se escuchan durante el baile? ¿Qué banda de pueblo eligen? ¿Qué personajes predominan en la partida? ¿Lleva la partida o alguno de sus bailadores o bailadoras algún mensaje político implícito o explícito? ¿Cómo es el descanso? ¿A los bailadores les interesa o no que las autoridades políticas del cantón visiten su descanso? ¿Cómo ponen el baile y el disfraz a juicio de la audiencia para legitimar su representación como auténtica y/o tradicional? ¿Cómo se definen y redefinen las identidades?

"Las formas de representación cultural, entendidas como prácticas performativas y generadoras de experiencia, constituyen espacios donde las identidades y las relaciones entre los participantes se crean, transforman y negocian" (Cánepa Koch, 2001, p. 18). A través de la danza, la fiesta o el ritual, se produce una continuidad entre lo representado y quien lo representa. Esta continuidad de identidades se verifica en el cuerpo, porque se convierte en el medio y en el mensaje, en el objeto y en el sujeto de la representación. Esto permite a las danzas y fiestas en general, y a la Diablada Pillareña en específico, ser un escenario importante para la definición y la redefinición de identidades (Cánepa Koch, 2001). Es así que la fiesta de la Diablada Pillareña, vista como una cultura expresiva, es un todo a la vez: ritual, juego, danza, teatro, feria, comida, identidad, relaciones de poder, trabajo, economía, relaciones afectivas, entre otros (Landy, 2019). Es la vida misma a pequeña escala (Bajtin, 2005).

\section{Cambios en las festividades andinas}

Muchos de los cambios en las fiestas andinas obedecen a "una suma de factores no festivos, no religiosos, no devocionales y no locales" (Diez Hurtado, 2001, p. 396). La expansión del Estado, la creciente institucionalización de prácticas culturales (Mendoza, 2001), la patrimonialización (Landy, 2019), el turismo y las 
tecnologías de la comunicación (Diez Hurtado, 2001), resultan algunos de los factores más influyentes en los cambios y transformaciones de las fiestas andinas en los últimos años. Para Alejandro Diez Hurtado (2001) existen al menos tres tipos de cambios observados en las festividades andinas: cambios periféricos, que tienen que ver con los sucesos que ocurren de un año al otro y que no son considerados cambios significativos; cambios complementarios, que modifican algún aspecto de la celebración, pero que no alteran su patrón general, y cambios desestructurantes, que modifican el patrón o sentido de la celebración o la descontextualizan (Diez Hurtado, 2001, p. 370).

Estos cambios ocurren a la par, unas veces de forma leve y otras de forma aguda. Con el paso del tiempo la suma de estos cambios puede producir transformaciones importantes en las experiencias y en los significados que la gente encarna, en cómo la gente vive e interpreta la fiesta (Diez Hurtado, 2001). El personaje del diablo de Píllaro, asociado a lo sucio, lo salvaje o lo violento, era visto de manera peyorativa pues encarnaba nociones indígenas. Con el tiempo, pasó a representar fundamentos mestizos, con más precisión, pillareños, asociados a un discurso insurgente, en el marco de una conexión local-global en la que la identidad étnica o pertenencia a un pueblo o ciudad muestra un lugar de enunciación y una ubicación en el mundo (Cánepa Koch, 2001).

Los cambios periféricos en la Diablada Pillareña tienen que ver con episodios esporádicos que influyen en una parte de la celebración, pero no en el todo, por ejemplo, el cambio de cabecilla en una partida, el cambio de una banda de pueblo en una partida, la proliferación de un personaje, entre otros. Los cambios complementarios refieren, principalmente, a cuestiones que modifican instancias grandes de la celebración, pero que no cambian el sentido, la interpretación, la experiencia o los significados encarnados. Estos son: el aumento de participantes en la fiesta (Diez Hurtado, 2001), nuevas partidas o eventos paralelos a la diablada, como el concurso literario con el tema "Diablada Pillareña" llevado a cabo en la edición de 2020 o la intervención de la diablada infantil en las ediciones 2019 y 2020 . También son cambios complementarios el incremento de comerciantes, artesanos, colectivos culturales, negocios de alquiler de disfraz, comida típica, entre otros. Como cambios desestructurantes, que modifican significativamente la interpretación y el significado encarnado de la fiesta (Diez Hurtado, 2001), ubico la eliminación de los enfrentamientos a inicios de la década de 1990 y la declaratoria patrimonial de la diablada en 2008 (Landy, 2019).

\section{La eliminación de los enfrentamientos}

Se dice que la Fiesta de Inocentes fue una fiesta que no tuvo injerencia política, religiosa o institucional, que respondía a la voluntad de los bailadores y a la suma de afectos que se concatenaban para una contribución económica voluntaria que sostenía los gastos de la práctica festiva (Bonilla, entrevista personal, 18 nov. 2019). Los bailadores, por lo general amigos, familiares, allegados, vecinos y conocidos del barrio Tunguipamba y de la parroquia Marcos Espinel, se agrupaban en torno a la figura de un líder local, "un buen anfitrión” (Landy, 2019, p. 44), un hombre que tenía capacidad económica para afrontar los gastos de la partida de disfraces, que poseía un sitio definido para los 
repasos y las salidas los días de la fiesta y que contaba con el apoyo de redes familiares para la elaboración de comidas y bebidas (Bonilla, entrevista personal, 18 nov. 2019; Espín, 2019). Esta figura era el cabecilla, un organizador y animador de la celebración, Paola de la Vega ${ }^{10}$ recogió el testimonio de Luis Álvarez ${ }^{11}$, cabecilla de Guanguibana en 2015:

\section{En ese tiempo sabíamos cobrar dos sucres por persona para que bailen de diablos. Vuelta lo que faltaba para la banda, fiábamos unos veinte o cuarenta sucres. Noso- tros salíamos perdiendo bastante, pero era el gusto de bailar, de tener en la casa la banda, los disfrazados. Para los ensayos me voy a ver por La Merced a los músicos de violín y guitarra. Ellos cobran y yo pago. He sido bien aficionado a la fiesta, por eso pago sin problema. Plata nomás es (2015).}

En este testimonio $y$ en los diferentes discursos locales pillareños (Bonilla, entrevista personal, 18 nov. 2019; Espín, 2018; Romero, 2015; Landy, 2019; Mask Collective \& Alianza Francesa del Ecuador, 2016) se recalca el gusto por la fiesta, el baile y la banda, independientemente de la inversión realizada para la celebración. De la misma manera, muchos bailadores y bailadoras, que aportan dinero en las partidas, no esperan obtener réditos económicos de su participación. La fiesta, a finales de la década de 1980, era una celebración local, considerada una fiesta de los campesinos que, atravesados por la convivencia cotidiana y el gusto por la música y el baile, se juntaban y con "sentido de pertenencia, voluntad, solidaridad, querencia y arraigo por la tierra" (Bonilla, entrevista personal, 18 nov. 2019), se disfrazaban para formar una partida. Se llama partida porque los integrantes "parten", "salen" o "provienen" de un barrio, caserío o parroquia rural (Espín, 2019) y se desplazan bailando hasta el centro o la Matriz de Píllaro, específicamente al emplaza- miento del parque y la iglesia, considerados los sitios del poder civil y religioso:

La gente de antes se reconocía como un solo cuerpo, como unidad, como un solo grupo, danzaba con un solo fin: apropiarse efímeramente, temporalmente, de los espacios de poder y legitimar a sus comunidades. Durante todo el año, Tunguipamba, Guanguibana, o cualquiera de las comunidades participantes son simplemente eso, barrios de la parte rural; pero al momento del año nuevo, esas comunidades pasan a ser el centro de atención de todo. (Bonilla, entrevista personal, 18 nov. 2019)

Para conseguir esa unidad, ese cuerpo colectivo en la partida, todos o casi todos los participantes se conocían entre sí, establecían lazos filiales o de parentesco que iban más allá de la fiesta. Las personas se organizaban a través de acuerdos informales y reglas implícitas entre los participantes, con poca influencia normativa o legal de los estamentos gubernamentales, civiles o religiosos (Bonilla, entrevista personal, 18 nov. 2019). Los disfraces eran sencillos, poco suntuosos, se utilizaban prendas improvisadas, preferiblemente de mujer, que impedían que los espectadores pudieran reconocer al bailador (Bonilla, entrevista personal, 18 nov. 2019).

Las caretas fueron confecciones pequeñas de papel engomado, pintadas en tonalidades negras y rojas. Destacaban los cachos de papel y alambre, los cuernos de venado, los colmillos cruzados, la nariz aguileña y los pómulos en los cachetes que provienen de la creatividad de los artesanos cuando imaginaron un demonio fuerte y poderoso que grita: jargh! Esta exclamación o rugido caracteriza la estética de la careta del diablo pillareño (Espín, 2019). El proceso de confección se denomina localmente "papel engomado" y consiste en superponer en un molde de yeso o cangagua diferentes capas 
de papel con engrudo hasta formar los rasgos principales. En las caretas de aquella época se buscaba el anonimato, que ayudaba a desatar la picardía en el baile y la violencia en las afrentas, y/o que protegían al bailador, puesto que era vergonzoso disfrazarse de diablo porque remitía a nociones campesinas (Landy, 2019).

Las partidas de Tunguipamba, Marcos Espinel y Guanguibana, creadas en la época de los enfrentamientos, se consideran pioneras o precursoras de la diablada (Bonilla, entrevista personal, 18 nov. 2019). Pero a finales de la década de 1980, las batallas festivas escalaron de manera exponencial. Lo que en un principio fueron grescas amorosas, rivalidades barriales, pugnas por ganar la esquina o "el sentido de libertad y rebeldía de un pueblo ancestral" (Reino, 2006, p. 39), se convirtieron en salvajes golpizas: el gusto por el baile fue reemplazado por el gusto por la pelea (Chasi, entrevista personal, 8 dic. 2019). Los disfraces no buscaban asustar o permitir un baile estético, sino que incorporaban elementos específicos para agredir: aciales, cadenas, ortigas, espinos. Los conflictos involucraron a los espectadores, al punto que muy pocos habitantes del centro o la Matriz salían de su casa para observar la celebración. Los desmanes alcanzaron la propiedad pública y privada, varias instancias policiales y civiles se levantaron en contra de la fiesta.

Para los años 1987, 1988, 1989, la Fiesta de Inocentes era una celebración deslucida (Chasi, entrevista personal, 8 dic. 2019). Las autoridades prohibieron expresamente a los cabecillas organizar las partidas de disfraces y se estableció que los perjuicios económicos ocasionados por los enfrentamientos deberían ser reparados por estos. Con la amenaza en marcha, se redujo el número de participantes, se mermó el entusiasmo y, poco a poco, la fiesta cayó en riesgo de extinción (Chasi, entrevista personal, 08 dic. 2019). Según Timoteo Chasi, en 1989 no hubo partidas de disfraces ni diablos (Chasi, entrevista personal, 08 dic. 2019). Según Néstor Bonilla, sí hubo diablos, aunque su celebración fue a pequeña escala (Bonilla, entrevista personal, 18 nov. 2019).

El gusto por la fiesta, el baile, la música y el disfraz permitió que muchos de los bailadores encontraran un nuevo cabecilla en la figura del líder local Timoteo Chasi, que inició un proceso para "blanquear", "civilizar", "transformar", "modernizar" o "culturizar" la fiesta. Chasi era un comprobado buen anfitrión, amigo de todos, un hombre de prestigio social y económico. En su casa en Rocafuerte organizaba canchullas y boliches ${ }^{12}$, tocaba ritmos bailables en arpa y guitarra, convocaba a la gente con su carisma en torno a la verbena nocturna: con juegos, música, bebida, comida y conversa. El barrio Rocafuerte, aunque pertenece a la parroquia Marcos Espinel, se ubica casi a la misma distancia del barrio Marcos Espinel (central) y de Tunguipamba, por tanto, habitantes de ambos sectores asistían a las veladas organizadas por Chasi. Si bien la gente de estos lugares rivalizaba en torno a la fiesta, mantenía relaciones cordiales el resto del año, evidenciando, como sostiene Pedro Reino, que las peleas refieren más a un espíritu festivo que a riñas barriales permanentes (2006).

Para 1990, Timoteo formó una nueva partida, hizo trámites y averiguaciones, obtuvo el apoyo de la intendencia y la comisaría siempre y cuando se garantizara la eliminación de las peleas (Chasi, entrevista personal, 8 dic. 2019). Para Chasi, los enfrentamientos no tenían nada de festivo o "cultural", eran un acto salvaje y violento que debía transformarse para dar 
paso a una celebración tradicional, "bonita", "cultural" (Chasi, entrevista personal, 08 dic. 2019). Timoteo pactó con los bailadores y con los pobladores del centro: se organizaría una partida desde su casa en Rocafuerte, con bailadores de Tunguipamba, Guanguibana, Marcos Espinel y otros sitios ${ }^{13}$, que evitaría los enfrentamientos. En palabras de Timoteo, desde el primer año "fue un éxito" (Chasi, entrevista personal, 08 dic. 2019).

Este éxito se debió a la gran cantidad de participantes, el gozo liberado y la reformulación de una fiesta sin enfrentamientos. Según Chasi, la gente entendió que para seguir bailando debía terminarse esa costumbre (entrevista personal, 18 nov. 2019). Los habitantes del centro se incorporaron poco a poco a la fiesta; el número de bailadores y espectadores fue aumentando de forma exponencial, y la prensa local, regional y nacional llegó al poco tiempo. La partida de Rocafuerte fue invitada a participar en el icónico corso de la alegría de Ambato, capital de la provincia, un 6 de enero de 1996 (Chasi, entrevista personal, 08 dic. 2019), lo que dio inicio al largo periplo de "salidas" de baile ${ }^{14}$, tan común y extendido en la actualidad. Según Chasi, en aquel corso, ante la insistencia de periodistas y curiosos, él llamaría a su comparsa "Diablada Pillareña". Esta denominación fue adoptada luego por las instituciones públicas para promover la celebración (Chasi, entrevista personal, 08 dic. 2019).

Con este resurgimiento, regresaron, con nuevos bríos y jolgorios, las antiguas partidas, que habían permanecido a la sombra pero no extintas. El baile sin enfrentamientos permitió una competencia entre partidas: cuál era la más afrentosa, la más temida, la más fuerte. Las caretas empezaron a adquirir rasgos particu- lares, se agrandaron los tamaños, se incorporaron figuras zoomorfas que recuerdan a cerdos y/o serpientes. Los trajes se estilizaron, se les incorporaron consignas de pertenencia a los barrios o caseríos y aparecieron alas, capas, tridentes, dragones, entre otros (Espín, 2019). Los diablos comenzaron a portar animales vivos o disecados, vísceras, juguetes sexuales, imágenes pornográficas y más elementos grotescos para asustar a la concurrencia, que crecía y crecía.

Estos acontecimientos son un cambio desestructurante (Diez Hurtado, 2001). La festividad se modificó en una de sus raíces estructurales, pues perdió uno de sus componentes más importante: los enfrentamientos festivos rituales. Estos se asociaban a la identidad indígena por su violencia implícita, pero también porque en la división rural/urbano pillareña, los habitantes de la Matriz, percibidos como mestizos, en contraste con los de los barrios, parroquias o caseríos periféricos, vistos como campesinos, jamás se unieron al baile, por considerarlo una fiesta de "los longos", y realizaban otros disfraces.

La pérdida de los enfrentamientos permitió que nuevos participantes se fueran sumando a las partidas de disfraces, pero también que los antiguos bailadores comenzaran a considerarse a sí mismos menos indios. Este es un proceso complejo, relacionado con las identidades fluidas asimétricas (De la Cadena, 2004) y con las distinciones identitarias que se expresan públicamente a través de las danzas (Mendoza, 2002). Cuando se acaban los enfrentamientos, los habitantes de los caseríos rurales y los del centro pasan a interpretar el mismo personaje: el diablo, reemplazando así, de a poco, la división rural/urbano por la noción de pillareño insurgente. Si bien la transformación fue paula- 
tina y ofreció espacio a las polémicas, produjo un acercamiento entre otredades. Al finalizar la década, existían al menos cinco partidas: Tunguipamba, Marcos Espinel, Guanguibana, Rocafuerte y Chacata el Carmen.

A su vez, la pérdida de los enfrentamientos permitió que las instituciones públicas y privadas miracen con ojos benevolentes la práctica y como una forma de obtener réditos económicos explotando el alcance del naciente turismo cultural y el auge de las festividades andinas. Es así que una fiesta que tenía poca relación con la institución, la política y el turismo, se complejizó cuando entraron en juego los intereses financieros y electorales. Poco tiempo después de la pérdida de los enfrentamientos, las autoridades locales, el alcalde y los concejales del municipio de Píllaro crearon un fondo monetario para el auspicio de la celebración, fondo que con los años se convirtió en el pretexto para la institucionalización de la Diablada Pillareña gracias a una mala aplicación, por parte de las autoridades de turno, de la declaratoria patrimonial. Revisemos este proceso.

\section{Declaratoria patrimonial de la Diablada Pillareña}

Las primeras concepciones de patrimonio, que perduraron hasta la década de 1950 (Landy, 2019), se refieren a bienes históricos, como una colección de riquezas, rarezas y objetos artísticos bellos (Llull, 2005). Así, diversos actores sociales, desde posiciones dominantes, activaron procesos de patrimonialización relativos a objetos y valores de las élites occidentales, que en su momento se denominaron tesoros nacionales, con el afán de consolidar la idea de un pueblo culturalmente homogéneo (Díaz, 2015). El debate sobre el patrimonio cultural inmaterial $(\mathrm{PCl})$ tiene una trayectoria reciente. La categoría fue creada en la Convención de la UNESCO en México en 1984 para reflexionar sobre el rescate y la conservación de las prácticas culturales y el papel de los agentes sociales como productores de cultura (Teran, 2014). El concepto de PCI se establece en la Convención de la UNESCO de París en 2003, llamada Convención para la Salvaguarda del Patrimonio Cultural Inmaterial. Este comprendería los

[...] usos, representaciones, expresiones, conocimientos y técnicas -junto con los instrumentos, objetos, artefactos y espacios culturales que les son inherentes- que las comunidades, los grupos y en algunos casos los individuos reconozcan como parte integrante de su patrimonio cultural. Este patrimonio cultural inmaterial, que se transmite de generación en generación, es recreado constantemente por las comunidades y grupos en función de su entorno, su interacción con la naturaleza y su historia, infundiéndoles un sentimiento de identidad y continuidad, y contribuyendo así a promover el respeto de la diversidad cultural y la creatividad humana. (UNESCO, 2003)

Esta concepción incentiva la conversión de procesos culturales en objetos de museo, con una perspectiva que convierte las culturas expresivas (Cánepa Koch, 2001) en un espectáculo y que piensa la diversidad cultural como una herramienta globalizante (Bartolotto, 2014), en la que coexiste la globalización con la reafirmación de las identidades locales (Castells, 2005). La UNESCO clasifica y cataloga las prácticas culturales en cinco ejes: tradiciones orales; artes del espectáculo; rituales y fiestas; usos y conocimiento del hombre, la naturaleza y el universo, y técnicas de elaboración de artesanías tradicionales (Landy, 2019). 
En Ecuador, los procesos patrimoniales surgieron como política de Estado desde 1978 con la creación del Instituto Nacional de Patrimonio Cultural (INPC). La Carta Magna de 1998, que estableció un territorio multiétnico y pluricultural, sirvió de marco jurídico para la creación de leyes y reglamentos para el rescate y la salvaguarda del patrimonio tangible e intangible (inmaterial). Desde 2001 se ejecutaron 14 declaratorias (Landy, 2019). En 2003, Ecuador suscribió la Convención de la UNESCO en París ratificando así su compromiso con la salvaguarda y la gestión del patrimonio inmaterial.

La declaratoria de la Diablada Pillareña como "patrimonio cultural inmaterial del Estado", publicada en el Registro Oficial el 29 de diciembre de 2008 "como parte de un proceso de revalorización de las manifestaciones culturales vivas más importantes del Ecuador" (Landy, 2019, p. 3), se ampara en la Constitución Política de la República del año 2008 y se realiza a través del INPC, que establece las normativas y regulaciones sobre el patrimonio inmaterial, cobijado en el concepto del $\mathrm{PCl}$ del artículo 52 de la vigente Ley Orgánica de Cultura:

Art. 52. [...] [Patrimonio Inmaterial] Son todos los valores, conocimientos, saberes, tecnologías, formas de hacer, pensar y percibir el mundo, y en general las manifestaciones que identifican culturalmente a las personas, comunas, comunidades, pueblos y nacionalidades que conforman el Estado intercultural, plurinacional y multiétnico ecuatoriano. (Registro Oficial, 2016)

El Ministerio de Cultura, a través del INPC, en el Acuerdo Ministerial 147, proclama a la Diabla Pillareña PCl del Estado:

[...] considerando que sus tradiciones, expresiones orales, leyendas, mitologías, cuentos, coplas y creencias transmitidas de generación en generación, son únicas por su conservación y expresión festiva; por tanto, meritorias de reconocimiento como una de las expresiones patrimoniales vivas más importantes del país. (Ministerio de Cultura, 2008)

Al declarar a la diablada como $\mathrm{PCl}$ del Estado ecuatoriano se le utilizó como un instrumento institucional (Landy, 2019). A partir de él se espera que las instituciones pillareñas recopilen, clasifiquen, inventen y reinventen los elementos de la Diablada Pillareña y archiven en diferentes soportes, como grabaciones, videos o textos, los significados de la danza (Landy, 2019). Pero ya vimos que esta danza no tiene significados establecidos; más bien encarna experiencias y significados en el cuerpo de los participantes de acuerdo con dos niveles contextuales en cuanto cultura expresiva (Cánepa Koch, 2001). Esta visión institucional, descontextualiza la diablada y puede convertir a los sujetos vivos que la practican en piezas de museo (Díaz, 2015).

Es por ello que Carmen Landy (2019), integrante de la comisión de técnicos del INPC, retornó a estudiar los efectos de la patrimonialización diez años después, en 2018. Al abordar los cambios, transformaciones, continuidades y resignificaciones de la fiesta tras el proceso de patrimonialización, que duró 4 años, quedó claro que este implicó un antes y un después (Landy, 2019). Además, ligado a la patrimonialización, pero con su propia historia y narrativa, se encuentra el proceso de institucionalización, que modificó las relaciones de poder en lo relativo a la organización de la diablada y propició su utilización con fines partidistas, lo que fue cuestionado por los participantes (Landy, 2019).

Antes de la institucionalización, la organización económica pasaba por la suma de voluntades y afectos (Bonilla, entrevista personal, 18 nov. 2019). El aporte en dinero o en insumos 
para la consecución de la fiesta se realizaba entre vecinos, amigos y bailadores. A partir de la institucionalización, el Gad Municipal comezó a financiar a los cabecillas o líderes de cada partida y los bailadores dejaron de realizar un aporte económico significativo, lo que según Landy (2009) podría ir en detrimento del tejido comunitario de la fiesta.

Sin estar en desacuerdo, considero que no todas las transformaciones generadas a partir del patrimonio y la institucionalización son negativas, pues también se evidencia el florecimiento de colectivos culturales y talleres artísticos, a favor o en contra de los procesos institucionales, que aumentan las redes de relaciones sociales que se entretejen para definir y redefinir distinciones identitarias étnicas, de clase, de género o generacionales en la actuación pública de enero. Quizás el tejido comunitario de la fiesta no se eliminó, más bien se trasladó, se modificó, se adaptó a diferentes circunstancias, como lo ha venido haciendo a lo largo de los años.

La patrimonialización de los años 2008-2009 no es un proceso aislado, es una construcción de carácter histórico, social, político y económico, conformada por bienes y valores materiales e inmateriales (Velasco, 2009), que responde a la consolidación de un nosotros colectivo desde la memoria (Landy, 2019), a la conformación de una identidad nacional, y al capitalismo, el turismo y los Estados (Andrade Butzonitch, 2009). Es decir, la patrimonialización está conectada con procesos globales, como la expansión de los Estados, el multiculturalismo neoliberal (Díaz-Polanco, 2011), la política como espectáculo y/o la vida trasladada a las redes sociales (Ardévol \& Lanzeni, 2014). También la patrimonialización y la esfera del internet y las redes sociales virtuales se conectan con la mercantilización de la cultura: las industrias culturales, el turismo cultural, la economía de la cultura o las industrias creativas (García Canclini, 2011; Landy, 2019).

Carmen Landy critica con severidad la patrimonialización de la Diablada Pillareña. En calidad de técnica del INPC y luego investigadora particular, analiza la situación como un juego de poderes en donde esta institución fue juez y parte, cobrando por los estudios, revisándolos y ratificándolos ella misma. "Esta interacción se basa en el poder que se atribuye la capacidad de determinar qué manifestaciones culturales deben o pueden ser declaradas patrimonio, entrando así en el campo de la política" (Landy, 2019, p. 84). También critica duramente los estudios entregados por el INPC al municipio de Píllaro. Según su punto de vista, estos trabajos son someros e incipientes. El estudio histórico se enmarca en una perspectiva de "historia estructural" que no hurga en la memoria y en su interacción con la historia desde una relación problemática, que no busca la huella del pasado en el presente. Landy sigue a Walter Benjamin al afirmar que un listado de fechas y nombres desconectados de los ideales colectivos del presente es insuficiente para dar cuenta de un contexto histórico en torno a la fiesta (Landy, 2019).

El estudio antropológico, por otro lado, le dedica solo 8 de 43 páginas a la Diablada Pillareña. El $80 \%$ del documento se centra en referenciar la historia del diablo en Occidente, su llegada al continente americano, los procesos de evangelización, la apropiación simbólica de los nativos, otras diabladas del continente, entre otros. Coincido con Landy (2019) en que la estructura y el contenido del estudio muestran la "historia estructural" en detrimento de la información local: escueta e insuficiente. También estoy de acuerdo 
en afirmar que las caracterizaciones de la fiesta y las etapas que propone este escrito tienen como afán mostrar los datos de forma cronológica y que no responden a la compleja interacción con la realidad. Estos estudios también fueron criticados por los pillareños, quienes quedaron inconformes con los textos y resultados.

La declaratoria patrimonial ayudó a legitimar las políticas municipales implementadas con anterioridad, lo que terminaría por institucionalizar la celebración a través del Departamento de Cultura. De esta manera quedó establecido el ya popular nombre: "Diablada Pillareña" en reemplazo del nombre antiguo "Fiesta de Inocentes". El financiamiento pasó casi totalmente al municipio, el cual se encarga también de convocar a los cabecillas y bailadores, y a los turistas a través de la publicidad. Para Landy, leída desde Diez-Hurtado (2001), la declaración sería un cambio desestructurante.

Esta autora ubica los impactos en tres ejes: económicos, socioculturales y organizacionales (Landy, 2019). Los impactos en el eje económico dan cuenta del progresivo paso de una economía moral (Thompson, 1991), caracterizada por una austeridad cotidiana y transformada en despilfarro liminal en los días de fiesta, para dar paso al libre mercado, a la inserción del patrimonio como objeto de consumo (Landy, 2019). La fiesta, al tener un origen local, establece interacciones económicas desde una perspectiva territorial en pos del desarrollo de relaciones filiales, afectivas y de parentesco extendido, contagiadas por el arraigo de la fiesta y el gusto por el baile y el disfraz. Estos elementos, según Landy (2019), convocan a una resistencia a la economía de libre mercado, pues van siendo mermados en beneficio del turismo a gran escala y la empresa privada.
Por mi parte, no creo que estos elementos hayan quedado eliminados de la fiesta; quizá sean menos visibles o menos espectaculares, pero son componentes importantes de la diablada, una economía moral que no es una resistencia al libre mercado, sino que se integra a él, con sus lógicas particulares. En ese sentido, no es la declaratoria en sí, sino su instrumentalización, el auge de las redes sociales, del turismo cultural, de los mercados creativos, entre otros, los que se combinan para producir una fiesta-espectáculo que impide ver los intercambios económicos y afectivos que los bailadores seguimos realizando en el interior de las partidas.

En el eje sociocultural, Landy (2019) ubica algunos cambios complementarios en la confección de las caretas, la música, la elaboración de los alimentos y el comercio informal, aspectos que, si bien se modificaron sustancialmente con la declaratoria, también caminan de la mano con la institucionalización, la tecnología y el turismo. La elaboración de caretas, antes asignada a pocos artesanos, ahora es realizada por artistas, talleres y personas particulares con fines comerciales o no. Landy (2019) cree que es el turismo, producido a partir de la declaratoria, el que impulsa el auge de la elaboración de caretas. Esto es evidente, pero no es el único elemento, son una serie de factores externos, como el auge del multiculturalismo neoliberal (Díaz-Polanco, 2011) o las redes virtuales que difuminan los límites de lo online/offline (Ardévol \& Lanzeni, 2014), que se interrelacionan de manera compleja con aspectos locales, como el trabajo del Departamento de Cultura durante la primera década de 2000 con sus cursos vacacionales de caretas dirigidos a niños, niñas y adolescentes, que incidieron en la formación de colectivos culturales y de talleres artesanales asociados a la diablada. 
Landy (2019) también plantea la paradoja de una declaratoria y un discurso patrimonial ausente de los textos, discursos y conversaciones de los bailadores y bailadoras, que durante la fiesta activan una amplia gama de mitos y leyendas, de juegos y palabras claves, que no incluye la palabra patrimonio. Pero aunque el componente patrimonial no está muy extendido entre los bailadores, sí lo está entre los cabecillas, colectivos culturales, artesanos y otros actores que legitiman su rol en la fiesta con diversos discursos en medios de comunicación, salidas de baile o redes virtuales. Es decir, aunque para la mayoría de los participantes la declaratoria es una herramienta conceptual inentendible y alejada, existen otros que la utilizan para su beneficio social, económico, turístico o de legitimación. Los cabecillas mencionan las palabras "cultura", "tradición" o "patrimonio" cuando son entrevistados, los bailadores suben fotos a las redes sociales con la leyenda "somos patrimonio", los artesanos ubican sus caretas en ferias nacionales e internacionales bajo las lógicas y el discurso del patrimonio que, aunque vertical, permite el escamoteo de muchos de los actores para conseguir sus fines. Estoy en desacuerdo entonces con Landy, mi opinión es que el discurso patrimonial va siendo adoptado y adaptado por diversos sectores con diferentes objetivos.

Finalmente, en el eje organizacional, Landy (2019) ubica la frágil y problemática relación institución-partidas, un aspecto que, en mi criterio, sí representa un cambio desestructurante, puesto que traslada el eje organizativo de las comunidades al municipio. Anteriormente, eran los propios bailadores, cabecillas y acompañantes los gestores de los recursos materiales y económicos para la realización de la fiesta y quienes configuraban normas implí- citas y explícitas al momento del baile en enero. Actualmente, el municipio convoca, promociona y financia la diablada, de manera que se crea una disyuntiva municipio/partidas que no siempre llega a ponerse de acuerdo.

En 2015, la alcaldía estableció un decreto que cambiaba el recorrido de la diablada y que debía ser firmado por los y las cabecillas para desembolsar los fondos. Pillareños y pillareñas se manifestaron inconformes por esta resolución, aduciendo que el nuevo recorrido eliminaba el "tradicional" baile frente a la iglesia del cantón. El alcalde, su hermano (sacerdote) y el párroco de Píllaro iniciaron un discurso de respeto a la iglesia y sus virtudes, indicando que el baile de los diablos interfería en la liturgia de los primeros días de enero. Tales argumentos fueron cuestionados por la mayoría de los pillareños y pillareñas, devotos y practicantes católicos en gran porcentaje, que no asocian la diablada a una manifestación religiosa. La tensión se mantuvo en ascenso durante los días previos a la diablada de 2015 y finalmente, el 1 de enero, la partida de Guanguibana violó las prohibiciones municipales y se enfrentó, en un acto simbólico, a las fuerzas del orden público e ingresó a las calles vedadas para bailar el "Píllaro Viejo" en un acto que sus protagonistas calificaron de insurgente y libertario (Bonilla, entrevista personal, 18 nov. 2019). Al día siguiente, el 2 de enero, la calle prohibida estaba cubierta de volquetas municipales que impedían cualquier atrevimiento por parte de las partidas y establecían la jerarquía vertical del municipio en la fiesta.

La creación de un recorrido representa un cambio desestructurante (Diez Hurtado, 2001): las partidas, que salían desde su barrio o caserío rural y se desplazaban bailando hasta 
las calles del parque, ahora debían integrarse a un trazado similar a un desfile; desafío imposible para la fiesta, debido a que cada partida proviene de una ubicación geográfica distinta y, por tanto, ingresa a las calles del parque por distintos lugares (Espín, 2019). Italo Espín (2019) considera que los sentidos originarios de la diablada eran una pugna entre barrios (partidas) por ganar la esquina del parque. Cada partida cumplía un trazado distinto signado por su sitio de salida y su sitio de descanso; lo único que tenían en común era que en su camino, de la salida al descanso y viceversa, atravesaban la calle de la iglesia. Por eso se consideraba la calle principal de la fiesta, porque todas las partidas bailaban en ella en su movimiento por diferentes lugares del cantón.

\section{Patrimonio y turismo}

Como indico a lo largo de la investigación en la que se basa este artículo, no es solo la declaratoria patrimonial la que propició cambios desestructurantes, sino, más bien, su interrelación con las instituciones, la tecnología y el turismo. El turismo es uno de los desafíos más grandes de la Diablada Pillareña y de las prácticas culturales patrimoniales en general. Si bien los visitantes y espectadores aumentaron de forma leve en las décadas de 1990 y 2000, su crecimiento fue exponencial a partir de la declaratoria patrimonial en 2008.

La percepción sobre el turismo y los turistas revela algunas diferencias entre cabecillas, bailadores, bailadoras, espectadores, artesanos, comerciantes, alquileres de disfraces, entre otros. Para un sector pillareño importante, es necesario recibir al turismo y al turista de forma ordenada, moderna, estética y planificada, de manera que se puedan obtener réditos económicos de la actividad turística y de la diablada. Por eso las autoridades, los habitantes del centro o Matriz, los comerciantes, los emprendedores, los medios de comunicación, etc., piden a las partidas, cabecillas, bailadores y bailadoras "dar un buen espectáculo", hacer una fiesta sin alcohol y respetar a los turistas. De otro lado, algunos bailadores indican que pueden hacer la fiesta sin turismo, que los visitantes, muchas veces, entorpecen el desarrollo de la celebración.

Estas posiciones se relacionan de forma heterogénea y compleja, y producen diversas situaciones y comentarios. Para los habitantes del centro, comerciantes y emprendedores, la cuestión turística es fundamental: se llenan los hoteles, los negocios se abarrotan, los locales de comida no dan abasto, se venden caretas y artesanías, se alquilan trajes, entre otros. Muchos pillareños y pillareñas, prensa incluida, consideran vital el trato, el servicio y la consideración al turista, y sugieren alternativas y cambios para la fiesta que lo privilegian. Fruto de estas visiones e iniciativas surgió la idea del "diablódromo", que se trataba de construir un coliseo cerrado temporal, como si fuera una plaza de toros, para que los diablos bailen en la plaza y la concurrencia pueda verlos desde sus asientos, o la colocación de graderíos y la asignación de recorridos en cada diablada. La administración municipal y muchos pillareños y pillareñas consideran necesario tener un recorrido para que los turistas (y ellos mismos) puedan apreciar los bailes. Asumen que la falta de un recorrido causa confusión entre los espectadores. 
Incluso varios pillareños y pillareñas consideran que este recorrido debería salir de las calles céntricas y que habría que colocar la fiesta, como un desfile, en alguna avenida amplia y periférica de la ciudad para que los espectadores observen la diablada y las partidas no interfieran con los procesos cívicos-religiosos del cantón. Para estas voces, esta sigue siendo una fiesta campesina que, aunque aporta económicamente al cantón y se reviste de fama nacional, ensucia y afea las calles principales, por el desorden y la basura generados. Esta perspectiva que encubre, bajo el discurso turístico, antiguas negaciones y omisiones de la fiesta, revela diferencias identitarias étnicas: mientras unos se asumen habitantes del centro en defensa de sus calles principales, otros se toman simbólicamente, desde la ruralidad, con baile y símbolos, las mismas calles para recordar el rol cultural y económico primordial que juegan los habitantes campesinos en el cantón (Bonilla, entrevista personal, 18 nov. 2019).

Una parte de la ciudad considera imprescindible organizar la fiesta para los turistas, es decir, brindar facilidades para observar y participar de la diablada, alquilar trajes y ayudarlos a disfrazarse para que puedan integrarse a las partidas. Puesto que bailar en una partida es un acto libre y voluntario, muchos turistas llegan con el objetivo de bailar con los diablos. Alquilan trajes o confeccionan sus propios trajes y caretas, y después de pagar lo dispuesto por el cabecilla, se integran al jolgorio.

Estas voces se preocupan también por los descansos, pues consideran que en ese momento "no hay nada que ver" (Radio Brisa, 2020) en las calles, es decir las calles se quedan sin diablada porque los bailadores están en sus posadas. Desde el municipio se intenta dirigir a los turistas a los descansos, para que puedan compartir este espacio con los bailadores, pero también se crean horarios, se espera que mientras unas partidas descansen, otras atraviesan el parque, para brindar un espectáculo a los turistas que vienen a contemplar la diablada y en muchos de los casos se retiran decepcionados. Para este sector, que privilegia el turismo, es muy duro escuchar a los turistas criticar la Diablada Pillareña, quejarse de la falta de orden, de "que no se puede ver nada" o de que tuvieron que esperar horas para ver cómo una partida pasa durante cinco minutos por el frente, sin detenerse a bailar.

Estas disyuntivas se suscitan porque la mayoría de los turistas espera observar un desfile, sin detenerse en las particularidades de la fiesta. Muchos pillareños que privilegian el turismo, en lugar de generar estrategias para encaminarlo, prefieren sugerir cambios desestructurantes para la diablada, que terminarían por alterar los sentidos y las visiones comunitarias y campesinas, al convertir la fiesta en un desfile, en una pieza de museo (De la Vega, 2015; Espín, 2019; Bonilla, entrevista personal, 18 nov. 2019). Por otro lado, el turismo y los turistas reciben duras críticas por parte de algunas cabecillas y bailadores, que entienden a la perfección que los nuevos reglamentos y estatutos privilegian el espectáculo turístico sobre una fiesta local y rural. Para los sectores considerados por sí mismos como creadores y mantenedores de la fiesta, la diablada se puede hacer con o sin turistas, porque los turistas son menos importantes que la familia, los bailadores y los amigos, o que la querencia, el pago, el amor a la tierra.

Se critica así algunos aspectos del turismo como el alquiler de trajes, el baile del turista, el irrespeto al bailador local y los excesos alcohó- 
licos. Algunos pillareños y pillareñas, especialmente los bailadores y bailadoras, consideran el tumulto y el caos turístico un obstáculo para las partidas y para la toma simbólica de las calles del parque. Una cantidad excesiva de gente impide que los diablos tomen (bailen en) las esquinas. Muchos turistas, en su afán por ver o participar del jolgorio colectivo, empujan, golpean o insultan a los diablos y personajes que, intentando bailar, cuidar a las parejas, abrirse paso o asustar, son recibidos de forma agresiva e irrespetuosa por los turistas. Antaño, los espectadores escapaban, temían y respetaban a los diablos, ahora no lo hacen, alquilan trajes a precios módicos y se integran a bailar en las partidas. Por eso, algunos sectores los tachan de imitadores que no dominan los pasos de baile. Se dice que dan un mal espectáculo, que estorban y no dejan que los personajes cumplan su rol. Para este sector pillareño no se debería modificar la fiesta para beneficiar al turismo; más bien se debería fomentar otro tipo de turismo.

El turismo interacciona con la institución, el patrimonio y la tecnología para producir dinámicas heterogéneas y complejas, en las que cada pillareño y pillareña tiene su propia concepción. Es así como algunos gestores culturales, como Espín, Bonilla o Ángel Velasco ${ }^{15}$, o colectivos y grupos de bailadores, como Minga Cultural o La Gallada, desarrollaron estrategias para incorporar a los turistas a la diablada, encaminaron sus acciones para modificar su actuación durante la fiesta, en lugar de modificar la fiesta a la medida del turista. Néstor Bonilla fue uno de los primeros en "abrir" las puertas de su taller de caretas Supay ${ }^{16}$ a un incipiente turismo. Su perspectiva está dirigida a la transmisión de conocimientos a las nuevas generaciones y a la difusión de los sentidos de la Diablada Pillareña entre los investigadores, artesanos y artistas.
Italo Espín, por su parte, emprendió un proyecto turístico y de gestión cultural en torno a la Casa Cultural el Pacto, denominación de su casa y taller. Italo adecuó su hogar como museo, de manera que ofrece un paquete turístico completo, conectado a operadoras turísticas nacionales y en alianza con otros gestores y emprendedores pillareños. Al menos una o dos veces por mes, la casa-museo el Pacto se llena con visitantes de diferentes lugares del país. Italo revisa la historia de la estética de la fiesta, detalla los pasos para la elaboración de las caretas, ofrece un espectáculo con disfrazados y vende artesanías. Los visitantes recorren otros sitios emblemáticos de Píllaro antes de dejar atrás el cantón. Italo, además, ofrece talleres y cursos de elaboración de caretas, pintura, artesanías, entre otros. Ángel Velasco, por su parte, es más bien un artesano celoso. Sus alumnos y talleristas fueron sus hijos y su familia, que iniciaron procesos turísticos y de difusión en páginas de Facebook y en salidas de baile, utilizando la denominación Caretas Velasco.

Como se aprecia, el turismo puede ser un cambio complementario o desestructurante (Diez Hurtado, 2001), en concordancia con los objetivos y las visiones de los diferentes sectores pillareños. Algunos cabecillas y bailadores que se oponen al exceso de turistas en el centro de Píllaro, son excelentes anfitriones cuando estos turistas llegan hasta los barrios o caseríos rurales, donde debido a las características de la fiesta se establece una relación de encuentro entre turista-bailador. En los últimos años, cada vez más turistas llegan al lugar de partida, acompañan a los bailadores desde la salida, o llegan junto a la partida a la parte final, lo que demuestra el esfuerzo del turismo y del turista por entender las dinámicas de la diablada y adaptarse a ellas. 
Por otra parte, muchos turistas se decepcionan de la fiesta, porque no es un desfile en que las comparsas atraviesan la calle divirtiendo a la concurrencia, sino que es una toma simbólica, con sus características particulares, muy difíciles de asimilar con una o dos visitas aisladas. Y por supuesto, la mayoría de los bailadores nos quejamos año tras año del alquiler de trajes, del baile del turista, del irrespeto al espacio y al bailador local, de los excesos alcohólicos, del caos, del tumulto, de la ambiciosa idea de participar sin conocer, sin comprender, sin respetar ni interesarse en la historia o la gente local.

Los turistas aprecian el jolgorio de una fiesta de disfrazados que, casi como en trance, se deleitan asustando con una banda de pueblo. Se fijan en las caretas, se impresionan por su forma y su porte, por su tamaño y magnitud, miran los trajes, piden a las guarichas "un cariñito", gritan eufóricos "¡Viva Píllaro!" cuando pasan las partidas, esperando en recompensa un trago de licor. Este ¡Viva Píllaro! homogeniza los diversos y heterogéneos gritos de las partidas, que si bien también dicen ¡Viva Píllaro!, este viene seguido por un viva al lugar de procedencia de la partida. La mayoría de los turistas busca registrar la experiencia en fotografías y en videos que pueden o no incluirlos, para difundirlos en la red. Pocos comentan sobre la elegancia del baile, la forma y el color del pañuelo, el nombre de la banda de pueblo, el sector al que pertenece la partida; circunstancias que los pillareños averiguan desde el comienzo. Estos buscan y evitan a sus amigos y conocidos: los buscan para compartir y los evitan porque bajo el disfraz se pueden cometer pillerías. Entre las personas se comenta la calidad de cada partida bajo diversos criterios, por lo que cada una resulta la mejor en algún aspecto. Lo que quiero recalcar con estos detalles es que los lugareños aprecian una amplia gama de tenues diferencias y matices.

Algunos turistas son muy osados, llegan desde Ambato (capital provincial) en alguna ocasión, bailan una, dos, tres o hasta cuatro veces, para después decir que la fiesta no es solo de Píllaro, sino que es de la provincia, cuando en realidad están muy lejos de comprender la sutil mirada y memoria de los pillareños y pillareñas. El turismo masivo omite en sus recorridos esos pequeños sentires, esas pequeñas costumbres locales, como "pedir la lección" al chorizo, enamorarse en el baile de pareja de línea, los diferentes vivas que gritamos, el anonimato en las caretas, proteger a las parejas, la elegancia de su baile, los colores del pañuelo, la jerga y las palabras clave, la importancia del descanso y de la fiesta final, entre otros (Bonilla, entrevista personal, 18 nov. 2019). Cuestiones sencillas pero vitales en una fiesta que tiene sus códigos propios y lejanos a los del turismo masivo.

\section{Conclusiones}

A lo largo de treinta años (1990-2020), la Diablada Pillareña ha tenido cambios periféricos, que tienen que ver con los sucesos que ocurren de un año al otro y que no son considerados cambios significativos, como el incremento de participantes o el cambio de un cabecilla. Ha tenido asimismo cambios complementarios, que configuran nuevos escenarios o los amplían sin alterar el sentido de la celebración, como la creación de nuevas partidas; y también cambios desestructurantes, que modifican, alteran o descontextualizan el sentido de la celebración (Diez Hurtado, 2001). Los momentos desestructurantes y decisivos son: 


\section{La pérdida de los enfrentamientos rituales,} acaecida a inicios de los años noventa. Los enfrentamientos se asociaban a la identidad indígena por su violencia implícita, pero también porque en la división rural/urbano pillareña los habitantes de la Matriz, percibidos como mestizos, en contraste con los de los barrios, parroquias o caseríos periféricos, percibidos como campesinos, jamás se unieron al baile por considerarlo una fiesta de "los longos", y realizaban otros disfraces. La pérdida de los enfrentamientos permitió que nuevos participantes se sumaran a las partidas, pero también que los antiguos bailadores se considerasen a sí mismos menos indios. Este es un proceso complejo, vinculado a las identidades fluidas asimétricas (De la Cadena, 2004) y a las distinciones identitarias que se expresan públicamente a través de las danzas (Mendoza, 2002). Cuando se dejaron de hacer los enfrentamientos, los habitantes de los caseríos rurales y los del centro pasaron a interpretar el mismo personaje: el diablo, reemplazando de a poco la división rural/urbano por diversas nociones de insurgencia, tradición y/o autenticidad.

2. La declaratoria patrimonial que, en sí, no es un cambio desestructurante, pero su instrumentalización, el auge de las redes sociales, del turismo cultural y de los mercados creativos, entre otros, se combinaron para producir una fiesta espectáculo que descontextualiza la toma simbólica de las calles y que es interpretada como un desfile al servicio del turista y del comercio, lo que limita sus elementos y la convierte en un objeto vendible, estático, "una pieza de museo". La Fiesta de Inocentes, los disfrazados o los diablos, se transformaron en la Diablada Pillareña, a la par que se modificaron algunos de sus componentes: el financiamiento y la organización de la fiesta pasó de ser un aporte voluntario y generoso de los bailadores y bailadoras, a provenir de un fondo institucional, regulado por el municipio y sus estatutos. Con ello la autoridad quedó a cargo de gestionar los horarios, los recorridos, los permisos de uso de suelo, entre otros.

La Diablada Pillareña, en su edición de 2020 no fue una repetición de diabladas anteriores, aunque sí resultó una fiesta con fuerte arraigo en el campo, el gusto por el baile, la música y el disfraz, pero relacionada estrechamente con las instituciones, el discurso patrimonial, el turismo y la tecnología. Y los cambios no acaban nunca, pues para la edición de 2021, la fiesta se adaptó a las nuevas circunstancias sanitarias: existieron actividades legales e ilegales que actualizaron las disputas en torno a los motivos del baile, la insurgencia y el turismo. Mientras que el municipio de Píllaro prohibió la fiesta y organizó un baile reducido con representantes de cada una de las partidas, los bailadores se organizaron por su cuenta y violaron las prohibiciones municipales.

Frente al temor del contagio, al miedo de propagar la enfermedad en los hogares y a las posibles infracciones penales, los bailadores eligieron tomar su careta y transfigurarse en personajes de leyenda, demostrando que la fiesta pervive aunque el mundo se caiga a nuestro alrededor. Y, sobre todo, que la fiesta es un gusto personal para cada bailador porque al bailar se conecta con el ande, la música, el disfraz, con su memoria, su cuerpo y su experiencia para encarnar una identidad, un lugar en el mundo. La Diablada Pillareña 2021 nos recordó que el turismo y el negocio son secundarios para los bailadores, que sus corazones, su espíritu y su voluntad no están a la venta, ni se exhiben exóticos en vitrina; nos recordó que el gusto por el baile siempre será invaluable, íntimo, clandestino e insurgente. 


\section{Notas}

${ }^{1}$ Barrios y caseríos considerados rurales o periféricos por los pillareños y pillareñas, aunque cuenten con infraestructura vial, uso de suelo y cobertura de servicios básicos y pago de impuestos de zona urbana.

${ }^{2}$ La banda de pueblo, conformada por uno o dos bombos, un tambor, platillos, tres o cuatro trombones, tres o cuatro trompetas, tres o cuatro saxos (puede incluir además clarinetes, güiro, timbales, tubas, entre otros); interpreta san juanitos, tonadas y pasacalles principalmente.

${ }^{3}$ El personaje más popular y el que da nombre a la celebración. Los pillareños y pillareñas elaboran sus propias caretas, pelucas, coronillas, vestidos y boyeros para la ocasión. Su misión es "abrir espacio" para el baile de las "parejas de línea". Su baile es desgarbado y sucio. Intenta asustar y jugar con los y las observadoras.

${ }^{4}$ Personajes que representan a los "hacendados" o blanco-mestizos de alcurnia, llevan caretas de blanqueamiento (caretas de malla), pañuelos franceses, camisas, vestidos y pantalones adornados con papel brillante, su baile es acompasado y elegante.

${ }^{5}$ Este vocablo empleado en Colombia y Ecuador se refiere a una mujer (en la época de la colonia y en la conformación de la república) que suele acompañar o estar en presencia de los soldados en la campaña o en las marchas militares. En la fiesta, representan a mujeres de vida promiscua en el sentido machista y patriarcal de la costumbre. Son vistas como mujeres libertinas, parranderas e infieles.

${ }^{6}$ Representa a los barrenderos.

\section{Bibliografía}

Andrade Butzonitch, M. M. (2009). Poder, patrimonio y democracia. Andamios, Revista de Investigación Social, 6(12), 11-40.

Ardévol, E. \& Lanzeni, D. (2014). Visualidades y materialidades de lo digital: Caminos desde la antropología. Anthropologica, 32(33), 11-38.

Bajtin, M. (2005). La cultura popular en la Edad Media y el Renacimiento: El contexto de François Rabelais. Madrid: Alianza.

Bartolotto, C. (2014). La problemática del patrimonio cultural inmaterial. Culturas, Revista de Gestión Cultural, 1(1), 1-22.

Campaña, M. de J., Campaña, R., Ron, B. \& Robalino, C. (2010). Píllaro: Historia, tradición y leyenda 1933-2001. Ambato: Ministerio de Cultura del Ecuador.

Cadena, M. de la (2004). Indígenas mestizos: Raza y cultura en el Cuzco. Lima: Instituto de Estudios Peruanos.

Cánepa Koch, G. (2001). Formas de cultura expresiva y etnografía de lo local. En Cánepa Koch, G. (Ed.), Identidades representadas: Performance, experiencia y memoria en los Andes (pp. 11-31). Lima: Pontificia Universidad Católica del Perú.

Castells, M. (2005). Globalización e identidad. Cuadernos del Mediterráneo, 5, 11-20.

\footnotetext{
${ }^{7}$ Payasos que dan la lección: rima, verso o juego de palabras a los asistentes. La misión de estos últimos tres personajes es "abrir espacio" para el baile de las "parejas de línea".

${ }^{8}$ La mayoría de las partidas (pero no todas) se concentran en barrios o caseríos que tienen más altura en metros sobre el nivel del mar que la parroquia central, por lo tanto, la gente suele decir: "ya bajan los diablos".

${ }^{9} \mathrm{~A}$ inicios de los años noventa existían tres partidas, con el tiempo su número aumentó. En 2020 bailaron 14 partidas.

${ }^{10}$ Gestora cultural de ancestros pillareños; se desenvuelve como profesora en la Universidad Andina Simón Bolívar.

${ }^{11}$ Su hija, Magdalena Álvarez, es la actual cabecilla de Guanguibana.

12 Juegos locales pillareños.

${ }^{13}$ Bailadores de Chacata, de Cochaló, de Tasinteo, que participaban en las grescas en Marcos Espinel o en Tunguipamba, dependiendo del caso, y algunos habitantes del centro que se unían de forma incipiente.

${ }^{14}$ Se denomina así cuando un grupo de disfrazados acude a bailar en alguna ciudad, fiesta o situación importante. Muchas veces estas salidas se pagan en efectivo, otras veces en favores.

${ }^{15}$ Destacado artesano pillareño con amplia experiencia.

${ }^{16}$ Néstor Bonilla cuenta con un amplio e interesante catálogo de caretas propias, donadas, intercambiadas y compradas, de diferentes épocas de la diablada.
}

Díaz, G. C. (2015). El patrimonio como recurso para vivir. (Tesis inédita de doctorado). Universidad de Sevilla, Sevilla.

Díaz-Polanco, H. (2011). Diez tesis sobre identidad, diversidad y globalización. En Chenaut, V., Gómez, M., Ortiz, H. \& Sierra, M. T. (Coords.), Justicia y diversidad en América Latina: Pueblos indígenas ante la globalización (pp. 36-62). Quito, México: Centro de Investigaciones y Estudios Superiores en Antropología Social Facultad Latinoamericana de Ciencias Sociales.

Diez Hurtado, A. (2001). Cambia lo superficial... ¿Cambia también lo profundo? En Cánepa Koch, G. (Ed.), Identidades representadas: Performance, experiencia y memoria en los Andes (pp. 367-396). Lima: Pontificia Universidad Católica del Perú.

Espín, I. (2018). Diablos de Píllaro. Antropología en 35mm: Flacso Radio [video-radio]. FLACSO, Quito. (2019). Archivo del silencio con Italo Espín, 12 diciembre.

F. Vernaza, (Entrevistador).

García Canclini, N. (2011). Google es más poderoso que las cadenas de TV o las discográficas. Cultura N, Tecnología y Comunicación.

INEC (2014). Resultados del censo 2010 de población y vivienda 
en el Ecuador. Ambato: Instituto Nacional de Estadística y Censos.

Landy, C. (2019). Patrimonialización de la Diablada Pillareña. Cuenca: Universidad de Cuenca.

Llull, J. (2005). Evolución del concepto y de la significación social del patrimonio cultural. Arte, Individuo y Sociedad, 17, 177-206.

Mask Collective \& Alianza Francesa del Ecuador (2016) Diablada Pillareña: Píllaro-Ecuador. Píllaro: Mask Collective, Alianza Francesa del Ecuador.

Mendoza, Z. (2001). Definiendo el folclor: Identidades mestizas e indígenas en movimiento. En Cánepa Koch, G. (Ed.), Identidades representadas: Performance, experiencia y memoria en los Andes (pp. 149-178). Lima: Pontificia Universidad Católica del Perú. (2002). Al son de la danza: Identidad y comparsas en el

Cuzco. Lima: Pontifica Universidad Católica del Perú.

Ministerio de Cultura (2008). Acuerdo Ministerial 147. Quito: Gobierno del Ecuador.

Radio Brisa (2020). Análisis de la Diablada Pillareña [radio], 7 Enero. Píllaro.
Registro Oficial (2016). Ley Orgánica de Cultura, 30 diciembre, 1-34. Quito.

Reino, P. A. (2006). La Diablada Pillareña. Ambato: Universidad Técnica de Ambato.

Romero, J. (2015). Los diablos de Píllaro: Voces y sentidos de una práctica ancestral [video reportaje]. Quito: Omega Producciones.

Teran, R. (2014). Repensar el patrimonio: El caso del Centro Histórico de Quito. INPC, Revista del Patrimonio Cutural del Ecuador, 5, 10-17.

Thompson, E. P. (1991). La economía moral revisada. Barcelona: Crítica.

UNESCO (2003). Convención para la salvaguarda del patrimonio cultural inmaterial. París: UNESCO.

Vega, P. de la (2015). De cuando nos llamaron "Diablada". El Telégrafo, 12 enero.

Velasco, H. M. (2009). El patrimonio cultural como sistema de representación y como sistema de valor. Madrid: Colex. 